\title{
Phenolic profile, antioxidant and enzyme inhibitory activity of the ethyl acetate, methanol and water extracts of Capparis spinosa $\mathrm{L}$.
}

\author{
Bulent Kirkan (iD) 1,*, Olcay Ceylan (D) 1 , Cengiz Sarikurkcu (D) 1 , Bektas Tepe (D)1
}

\author{
${ }^{1}$ Suleyman Demirel University, Water Institute, TR-32260, Isparta, TURKEY \\ ${ }^{2}$ Mugla Sitki Kocman University, Faculty of Science, TR-48000, Mugla, TURKEY \\ ${ }^{3}$ Afyonkarahisar Health Sciences University, Faculty of Pharmacy, TR-03100, Afyonkarahisar, TURKEY \\ ${ }^{4}$ Kilis 7 Aralik University, Faculty of Science and Literature, TR-79000, Kilis, Turkey
}

\begin{abstract}
In this study, it was aimed to determine the phytochemical compositions and biological activities of ethyl acetate (EtOAc), methanol $(\mathrm{MeOH})$ and water extracts obtained from the aerial parts of Capparis spinosa L. As a result of spectrophotometric analyzes, $\mathrm{MeOH}$ extract was found to be richer in terms of both phenolics and flavonoids compared to other extracts [81.45 mg GAEs (gallic acid equivalent)/g and $36.57 \mathrm{mg} \mathrm{RE} \mathrm{(rutin} \mathrm{equivalent)s/g,}$ respectively], while chromatographic analyzes showed that the extract in question contains a significant amount of hepseridin $(72927.48 \mu \mathrm{g} / \mathrm{g})$, quercetin $(1335.88$ $\mu \mathrm{g} / \mathrm{g})$, hyperoside $(1227.73 \mu \mathrm{g} / \mathrm{g})$, and 4-hydroxybenzoic acid $(924.08 \mu \mathrm{g} / \mathrm{g})$. Phosphomolybdenum, 2,2-diphenyl-1-picrylhydrazyl (DPPH) and 2,2-azinobis(3-ethylbenzothiazoline-6-sulphonic acid) (ABTS) radical scavenging, Cupric Reducing Antioxidant Power (CUPRAC) and Ferric Reducing Antioxidant Power (FRAP) reducing and ferrous ion chelating activity tests resulted in superiority of $\mathrm{MeOH}$ extract [371.0, 44.93, 56.46, 91.77, 52.61 mg TEs (trolox equivalent)/g and $14.85 \mathrm{mg}$ EDTAEs/g, respectively]. On the other hand, EtOAc extract exhibited higher activity than other extracts in acetylcholinesterase (AChE), butyrylcholinesterase (BChE), $\alpha$-amylase, and $\alpha$-glucosidase inhibitory activity tests [3.29, $2.12 \mathrm{mg}$ GALAEs (galanthamine equivalent) $/ \mathrm{g}, 541.01$ and $1584.20 \mathrm{mg}$ ACEs (acarbose equivalent)/g, respectively]. The tyrosinase inhibitory activity test resulted in the superiority of $\mathrm{MeOH}$ extract $[41.90 \mathrm{mg}$ KAEs (kojic acid equivalent)/g]. A strong correlation was determined between the phenolic and flavonoid contents of the extracts and their antioxidant activities.
\end{abstract}

\section{ARTICLE HISTORY}

Received: Aug. 10, 2021

Revised: Sept. 30, 2021

Accepted: Oct. 20, 2021

\section{KEYWORDS}

Capparis spinosa, LC-ESI-MS/MS,

Antioxidant, Enzyme inhibitory, Chemical composition,

\section{INTRODUCTION}

Plants can be used in industries such as medicine, pharmacy, food, cosmetics, etc., due to their pharmacological/biologically active phytochemicals, and therefore, new plants are attracting the attention of researchers every day (Orphanides et al., 2016). Researchers have revealed that many phytochemicals such as polyphenols, flavonoids, flavonoids, etc. can be used as critical functional compounds in the treatment of many metabolic diseases (Ng et al., 2012). Since

\footnotetext{
*CONTACT: Bektas TEPE $\square$ bektastepe@yahoo.com Kilis 7 Aralik University, Faculty of Science and Literature, Department of Molecular Biology and Genetics, Kilis, Turkey
} 
plants have low cost and are sustainable sources of phytochemicals, it is of great importance to use those with proven biological/pharmacological activities for industrial use as an alternative to synthetic compounds (Samy et al., 2005; Ng et al., 2020).

Foods deteriorate over time due to lipid oxidation and lose their quality (Yanishlieva \& Marinova, 2001). The deterioration of foods with high lipid content can be delayed by the addition of compounds that prevent oxidation during processing. The most effective way to control lipid oxidation is to benefit from antioxidant compounds (Shahidi \& Zhong, 2015). These compounds can be found widely in plants and animals, as well as chemically synthesized. Polyphenols and tocopherols are among the most potent antioxidant compounds and are abundant in many vegetables, fruits and grains. In addition, there are various reports of compounds with antioxidant effects in fish, algae and shellfish (Shahidi \& Amarowicz, 1996; Amarowicz et al., 1999; Athukorala et al., 2003). In the last decades, researchers have focused on many plant species for the discovery of new and more effective natural compounds that can be used instead of synthetic antioxidants to extend the shelf life of foods. As a result of these studies, many antioxidant phytochemicals have been identified (Liyana-Pathirana et al., 2006; Shahidi \& Zhong, 2007; Cumby et al., 2008).

Plants are of particular interest to researchers because they contain phytochemicals with enzyme inhibitory activity as well as antioxidant activities. In the enzyme inhibitory activity studies intensified in recent years, it has been reported that some plant species or some phytochemicals found in these species exhibit inhibitory activity such as cholinesterase (Hung et al., 2008; Loizzo et al., 2010; Pinho et al., 2013), $\alpha$-amylase/ $\alpha$-glucosidase (Liu et al., 2017; Rasouli et al., 2017; Tan et al., 2017), tyrosinase (Kubo \& Kinst-Hori, 1999; Likhitwitayawuid, 2008; Maisuthisakul \& Gordon, 2009), etc.

Capparis spinosa L. is an industrial plant species distributed in western and central Asia and along the Mediterranean coastline (Trombetta et al., 2005; Rahimi et al., 2020). This herb has been traditionally used by people for many years in the treatment of various diseases (gout, rheumatism, etc.) (Romeo et al., 2007; Aliyazicioglu et al., 2013; Zhang et al., 2018). Local people living in countries bordering the Mediterranean coastline also frequently benefit from C. spinosa's analgesic properties (Fu et al., 2008). In studies conducted by researchers, it has been reported that the aerial parts, roots or seeds of the plant exhibit many biological/pharmacological activities (anti-allergic, immunomodulatory, anti-inflammatory, antimicrobial, anti-histaminic, antiviral, etc.) (Trombetta et al., 2005; Tlili et al., 2011; KulisicBilusic et al., 2012).

The aim of this study was to determine the chemical compositions of ethyl acetate (EtOAc), methanol $(\mathrm{MeOH})$ and water extracts obtained from $C$. spinosa by qualitative and quantitative chromatographic methods, in vitro antioxidant and to document their inhibitory activities on acetylcholinesterase (AChE), butyrylcholinesterase (BChE), $\alpha$-amylase, $\alpha$-glucosidase, and tyrosinase.

\section{MATERIAL and METHODS}

\subsection{Plant Material and Extract Preparation}

Aerial parts of $C$. spinosa was collected from Camlibel village, Kavaklidere, Mugla-Turkey ( 780 m., $37^{\circ} 248^{\prime} 9^{\prime} \mathrm{N} 28^{\circ} 27688^{\prime} \mathrm{E}$ ) (Herbarium number: O.1196). Dr. Olcay Ceylan (Mugla Sitki Kocman University) performed the identification of the plant material. Aerial parts of the plants were used as the study material to obtain EtOAc, $\mathrm{MeOH}$ and water extracts [extract yields: $10.20,11.31$ and $21.58 \%(w / w)$, respectively]. Details of the extraction procedure can be found in supplementary file. 


\subsection{Determination of the Phenolic Compositions of the Extracts}

Details of the spectrophotometric and chromatographic analysis were given in supplementary file (Zengin et al., 2017; Cittan \& Çelik, 2018).

\subsection{Biological Activity}

Details of the antioxidant (Apak et al., 2006; Tepe et al., 2011; Kocak et al., 2016; Zengin et al., 2017; Sarikurkcu et al., 2020) and enzyme inhibitory activity (Ozer et al., 2018) tests were given in supplementary file.

\subsection{Statistical Analysis}

Details of the relative antioxidant capacity index (RACI) (Sun \& Tanumihardjo, 2007) and statistical analysis can be found in the supplementary file.

\section{RESULTS / FINDINGS}

\subsection{Chemical Composition}

The total amounts of phenolic and flavonoid compounds of the extracts are given in Figure 1. According to the data obtained by spectrophotometric method, $\mathrm{MeOH}$ extract was found to be rich in both phenolics and flavonoids. The total amount of phenolic and flavonoid compounds of this extract was $81.45 \mathrm{mg}$ GALAEs/g and $36.57 \mathrm{mg} \mathrm{REs} / \mathrm{g}$, respectively. Although the amounts of phenolic and flavonoid compounds of EtOAc and water extracts were close to each other, the chemical compositions of these extracts were statistically different from each other $(p<0.05)$.

Figure 1. Amounts of total flavonoids and phenolics in the extracts of $C$. spinosa. Different letters (a, $\mathrm{b}, \mathrm{c})$ on the bars show that the relevant data are statistically different from each other $(p<0.05)$.

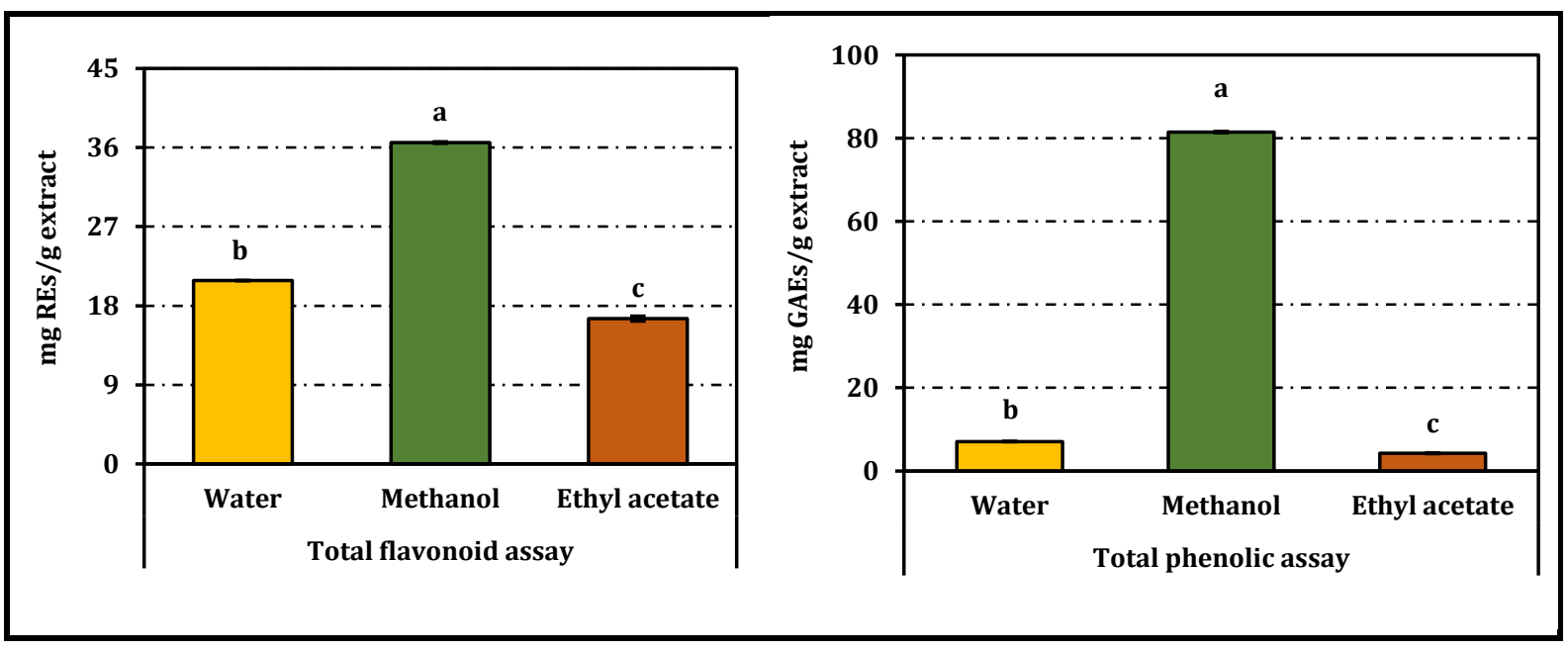

The chemical composition data of the extracts obtained by chromatographic methods are given in Table 1. According to the data in the table, it was understood that none of the extracts contained (+)-catechin, luteolin 7-glucoside, apigenin 7-glucoside, pinoresinol, kaempferol and luteolin. Chromatographic analyses showed that hepseridine was present in high amounts in the $\mathrm{MeOH}$ extract $(72927.48 \mu \mathrm{g} / \mathrm{g})$. Quercetin $(1335.88 \mu \mathrm{g} / \mathrm{g})$, hyperoside $(1227.73 \mu \mathrm{g} / \mathrm{g})$, 4hydroxybenzoic acid $(924.08 \mu \mathrm{g} / \mathrm{g})$ were also found in the $\mathrm{MeOH}$ extract. In addition to these phytochemicals, $p$-coumaric acid was also found in high amounts in EtOAc and water extracts.

\subsection{Antioxidant Activity}

The total antioxidant activities, reducing powers, radical scavenging and chelating capacities of the extracts are given in Figure 2. On the figures, the statistical relationship between the antioxidant activities of the extracts and each other is also indicated with small letters. 
In all antioxidant test systems presented in Figure 2, the $\mathrm{MeOH}$ extract exhibited significantly higher activity than the others. The activity value of this extract in phosphomolybdenum, DPPH and ABTS radical scavenging, CUPRAC and FRAP reducing and ferrous ion chelating assays were 371.0, 44.93, 56.46, 91.77, 52.61 mg TEs/g and $14.85 \mathrm{mg}$ EDTAEs/g, respectively. In the radical scavenging and ferrous ion chelating activity tests, the $\mathrm{MeOH}$ extract was followed by the water extract $(18.80,35.36 \mathrm{mg} \mathrm{TEs} / \mathrm{g}$ and $9.97 \mathrm{mg}$ EDTAEs/g, respectively), while the EtOAc extract ranked second in the phosphomolybdenum and CUPRAC reducing assays (329.40 and $48.34 \mathrm{mg}$ TEs/g, respectively). In the FRAP reducing assay, however, no statistically significant difference was found between the antioxidant activities of water and EtOAc extracts.

Table 1. Concentrations of selected phenolic compounds in the extracts of $C$. spinosa ( $\mu \mathrm{g} / \mathrm{g}$ extract).

\begin{tabular}{lccc}
\hline Compound & EtOAc & $\mathrm{MeOH}$ & Water \\
\hline Gallic acid & $3.84 \pm 0.02^{b}$ & $8.46 \pm 0.40^{a}$ & $3.80 \pm 0.10^{b}$ \\
Protocatechuic acid & $646.52 \pm 0.37^{a}$ & $179.25 \pm 2.86^{b}$ & $13.36 \pm 0.29^{c}$ \\
3,4-Dihydroxyphenylacetic acid & $13.36 \pm 0.43^{a}$ & $14.28 \pm 0.37^{a}$ & $14.76 \pm 0.19^{a}$ \\
Pyrocatechol & $26.39 \pm 0.14^{b}$ & $42.93 \pm 2.92^{a}$ & $33.11 \pm 1.04^{b}$ \\
(+)-Catechin & $\mathrm{nd}$ & $\mathrm{nd}$ & $\mathrm{nd}$ \\
Chlorogenic acid & $4.33 \pm 0.01^{a}$ & $4.06 \pm 0.10^{b}$ & $4.19 \pm 0.01^{a b}$ \\
(-)-Epicatechin & $2.61 \pm 0.09^{b}$ & $3.08 \pm 0.13^{a}$ & $2.41 \pm 0.02^{b}$ \\
2,5-Dihydroxybenzoic acid & $16.93 \pm 0.62^{a}$ & $11.75 \pm 0.90^{b}$ & $14.51 \pm 1.32^{a b}$ \\
4-Hydroxybenzoic acid & $648.78 \pm 1.04^{b}$ & $924.08 \pm 2.26^{a}$ & $106.19 \pm 3.28^{c}$ \\
Vanillic acid & $215.30 \pm 17.44^{b}$ & $305.77 \pm 14.43^{a}$ & $138.24 \pm 5.15^{c}$ \\
Caffeic acid & $12.91 \pm 0.85^{b}$ & $24.96 \pm 1.84^{a}$ & $14.13 \pm 0.43^{b}$ \\
Syringic acid & $9.74 \pm 0.06^{b}$ & $53.98 \pm 6.66^{a}$ & $5.65 \pm 0.10^{b}$ \\
3-Hydroxybenzoic acid & $10.64 \pm 0.60^{a}$ & $11.74 \pm 0.77^{a}$ & $11.39 \pm 0.23^{a}$ \\
Vanillin & $7.85 \pm 0.22^{c}$ & $19.42 \pm 2.16^{b}$ & $31.79 \pm 1.21^{a}$ \\
Verbascoside & $5.78 \pm 0.08^{a}$ & $6.04 \pm 0.13^{a}$ & $5.90 \pm 0.03^{a}$ \\
Taxifolin & $7.11 \pm 0.16^{c}$ & $15.60 \pm 0.11^{a}$ & $8.77 \pm 0.26^{b}$ \\
p-Coumaric acid & $144.54 \pm 0.56^{b}$ & $693.59 \pm 10.15^{a}$ & $34.32 \pm 2.24^{c}$ \\
Sinapic acid & $4.97 \pm 0.13^{c}$ & $33.80 \pm 0.14^{a}$ & $6.06 \pm 0.04^{b}$ \\
Ferulic acid & $71.80 \pm 1.21^{b}$ & $176.20 \pm 4.65^{a}$ & $13.39 \pm 2.38^{c}$ \\
Luteolin 7-glucoside & $\mathrm{nd}$ & $\mathrm{nd}$ & $\mathrm{nd}$ \\
Hyperoside & $4.53 \pm 0.19^{b}$ & $1227.73 \pm 16.22^{a}$ & $9.32 \pm 0.29^{b}$ \\
Hesperidin & $260.27 \pm 3.47^{a}$ & $72927.48 \pm 659.21^{b}$ & $155.34 \pm 1.26^{a}$ \\
Rosmarinic acid & $16.83 \pm 1.01^{b}$ & $28.82 \pm 0.63^{a}$ & $25.49 \pm 1.89^{a}$ \\
Apigenin 7-glucoside & $\mathrm{nd}$ & $\mathrm{nd}$ & $\mathrm{nd}$ \\
2-Hydroxycinnamic acid & $3.02 \pm 0.09^{b}$ & $2.06 \pm 0.07^{c}$ & $3.54 \pm 0.05^{a}$ \\
Eriodictyol & $9.56 \pm 0.12^{b}$ & $46.83 \pm 2.88^{a}$ & $13.64 \pm 0.11^{b}$ \\
Pinoresinol & $\mathrm{nd}$ & $\mathrm{nd}$ & $\mathrm{nd}$ \\
Quercetin & $5.42 \pm 0.15^{c}$ & $1335.88 \pm 6.51^{a}$ & $100.11 \pm 1.39^{b}$ \\
Kaempferol & $\mathrm{nd}$ & $\mathrm{nd}$ & $\mathrm{nd}$ \\
Luteolin & $\mathrm{nd}$ & $\mathrm{nd}$ \\
\hline Diffrent & & & \\
\hline
\end{tabular}

Different letters $(a, b, c)$ within the same row show that the relevant data are statistically different from each other $(p<0.05)$. nd: Not detected. 
The relative antioxidant capacity index (RACI) data (Figure 3), in which extracts were compared with each other according to their activity potentials, taking into account all the activities obtained from the antioxidant activity tests, confirmed the data obtained from the antioxidant activity tests. According to the data presented in the figure, the $\mathrm{MeOH}$ extract ranked first with a RACI value of 1.20. It was followed by water and EtOAc extracts with RACI values of -0.55 and -0.62 , respectively.

Figure 2. Antioxidative capacity of the extracts of $C$. spinosa. Different letters (a, b, c) on the bars show that the relevant data are statistically different from each other $(p<0.05)$.
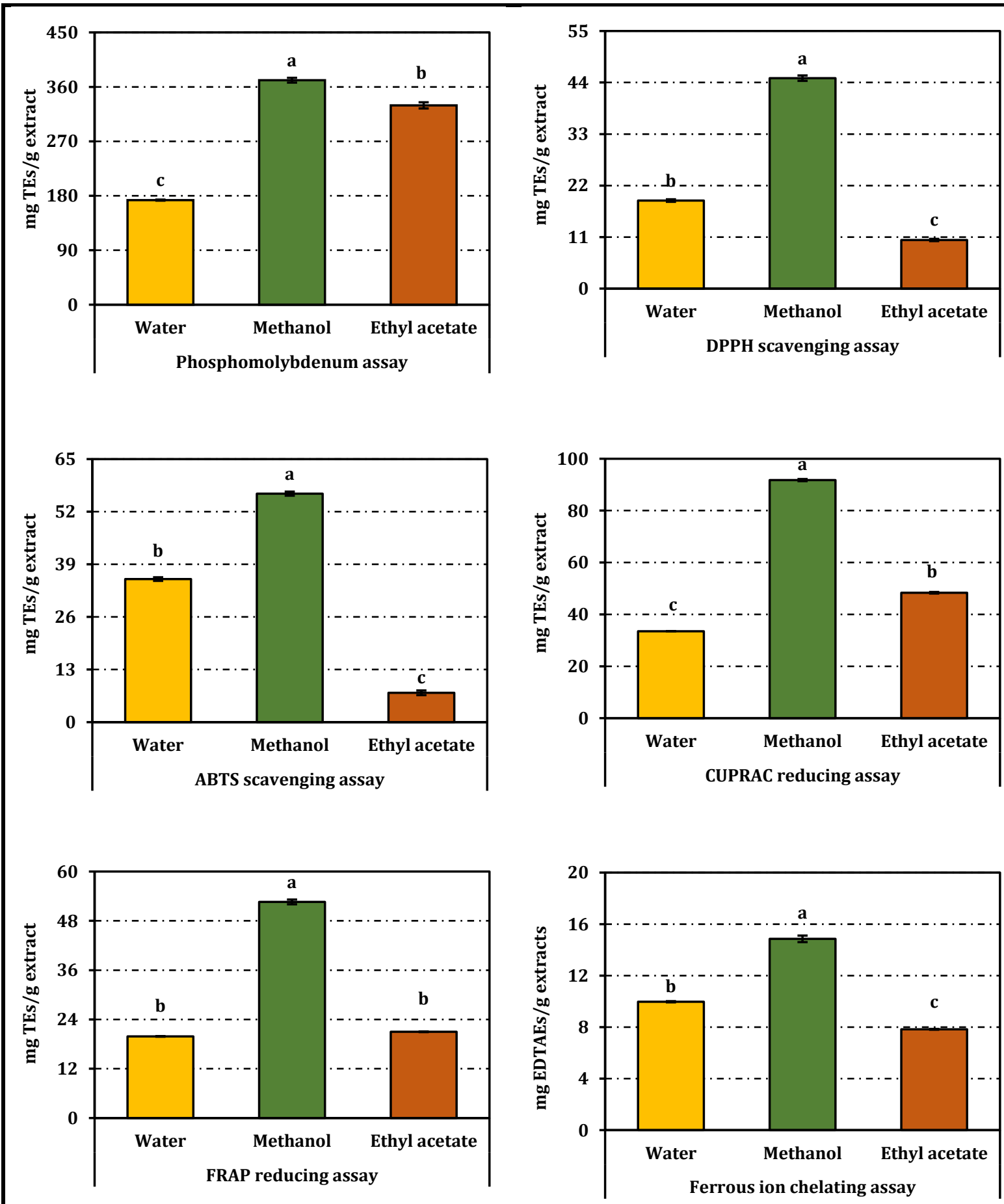
Figure 4 shows the correlation between the antioxidant activities of the extracts and their RACI values. A high correlation was found between the antioxidant activities of the extracts and the RACI values in all tests except the phosphomolybdenum assay. However, in the phosphomolybdenum test, the correlation between the total antioxidant activity of the EtOAc extract and the RACI value was found to be lower than in the other test systems.

Figure 3. RACI of the extracts of C. spinosa.

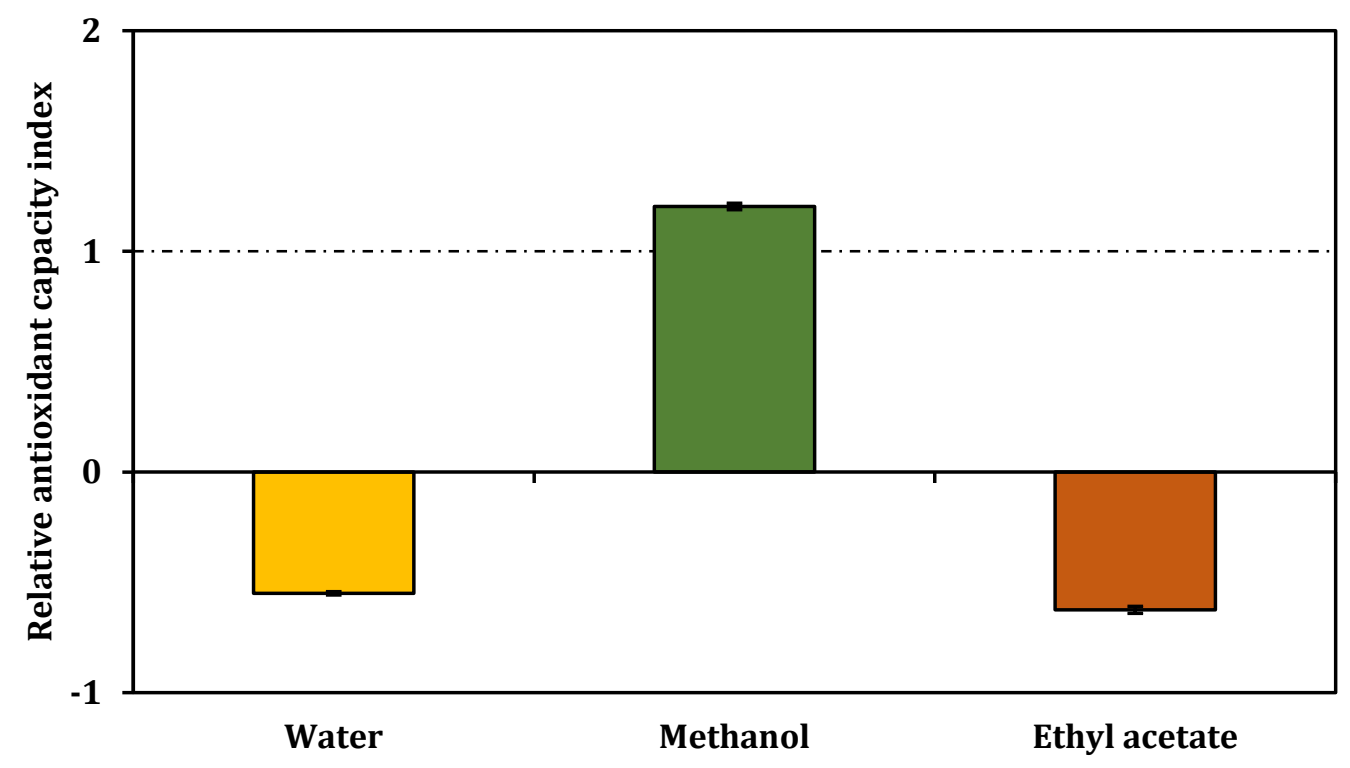

\subsection{Enzyme Inhibitory Activity}

Figure 5 shows the inhibitory activity potentials of $C$. spinosa extracts on AChE, BChE, $\alpha$ amylase, $\alpha$-glucosidase and tyrosinase.

As can be seen from Figure 5, EtOAc extract exhibited higher inhibitory activity than the others in all test systems except the tyrosinase inhibitor activity test. The inhibitory activities of the extract in question in $\mathrm{AChE}, \mathrm{BChE}, \alpha$-amylase and $\alpha$-glucosidase tests were $3.29,2.12$ $\mathrm{mg}$ GALAEs/g, 541.01, and $1584.20 \mathrm{mg}$ ACEs/g, respectively. The tyrosinase inhibitory activity test resulted in the superiority of $\mathrm{MeOH}$ extract (41.90 $\mathrm{mg} \mathrm{KAEs} / \mathrm{g}$ ). In this assay, no statistical difference was found between the activity potentials of the water and EtOAc extracts. While water and $\mathrm{MeOH}$ extracts were not active in the $\mathrm{BChE}$ inhibitory activity tests, the water extract remained inactive in the $\alpha$-glucosidase inhibitor activity assay.

\subsection{Correlation Coefficients}

Table 2 shows the correlation between the biological activity data of the extracts in the tests given above and their chemical compositions.

According to the correlation coefficients given in Table 2, there was a strong correlation between the phenolic and flavonoid contents of the extracts and their antioxidant activities (correlation coefficients were above 0.9). The relationship between these compounds and tyrosinase inhibitory activity was also found to be high. In addition, the relationship between protocatechuic acid, 4-hydroxybenzoic acid, vanillic acid, $p$-coumaric acid, ferulic acid, hesperidin, hyperoside, and quercetin contents of the extracts and their antioxidant and tyrosinase inhibitor activities were also found statistically significant. 
Figure 4. Antioxidant activity (solid dark blue line with circle) and RACI (dashed red line with triangle) of the extracts of C. spinosa.

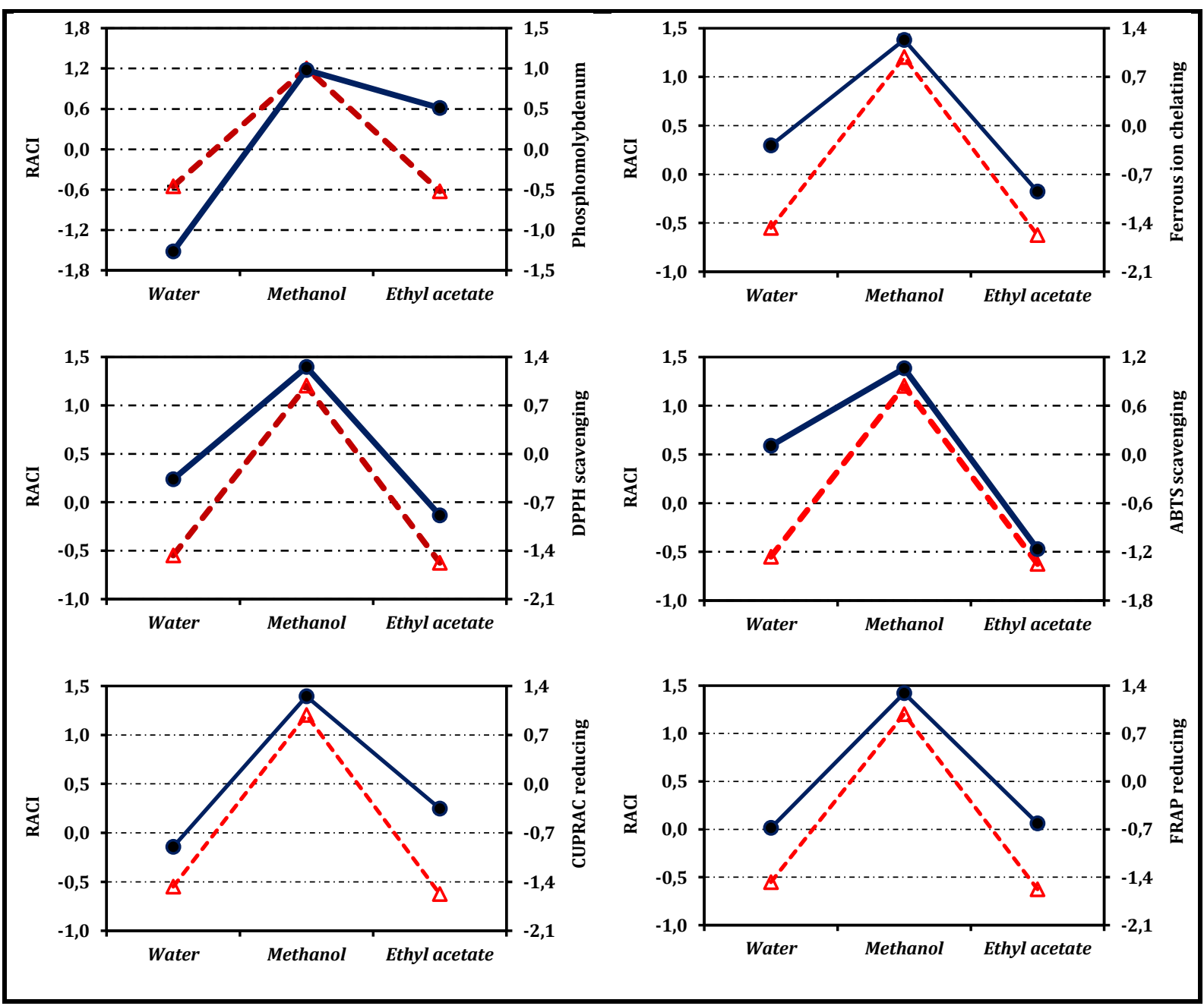

\section{DISCUSSION and CONCLUSION}

There are some data on the chemical composition of $C$. spinosa in the literature. According to these data, the presence of some tannins, saponins, alkaloids and flavonoids has been detected in this plant so far (Anwar et al., 2016; Snoussi et al., 2017). It is of course possible to elaborate on these studies. However, it is seen that some phytochemicals specific to this species come to the fore in some studies. In a study by Fu et al. (2007), cappariloside A and stachydrin were found to be the main components, while in some other studies, it was reported that rutin, which is a flavonoid, is found in high amounts in the plant (Stefanucci et al., 2018; Mollica et al., 2019). A review by Anwar et al. (2016) documented the flavonoids, alkaloids and essential oil components identified so far in C. spinosa. However, none of these studies included the presence of hepseridine and hyperoside, which were identified as the main compounds in the current study. Therefore, the presence of these compounds in C. spinosa was brought to the literature for the first time with this study. 
Figure 5. The capacity of the extracts of $C$. spinosa. to inhibit some enzymes. Different letters $(\mathrm{a}, \mathrm{b}, \mathrm{c})$ on the bars show that the relevant data are statistically different from each other $(p<0.05)$.
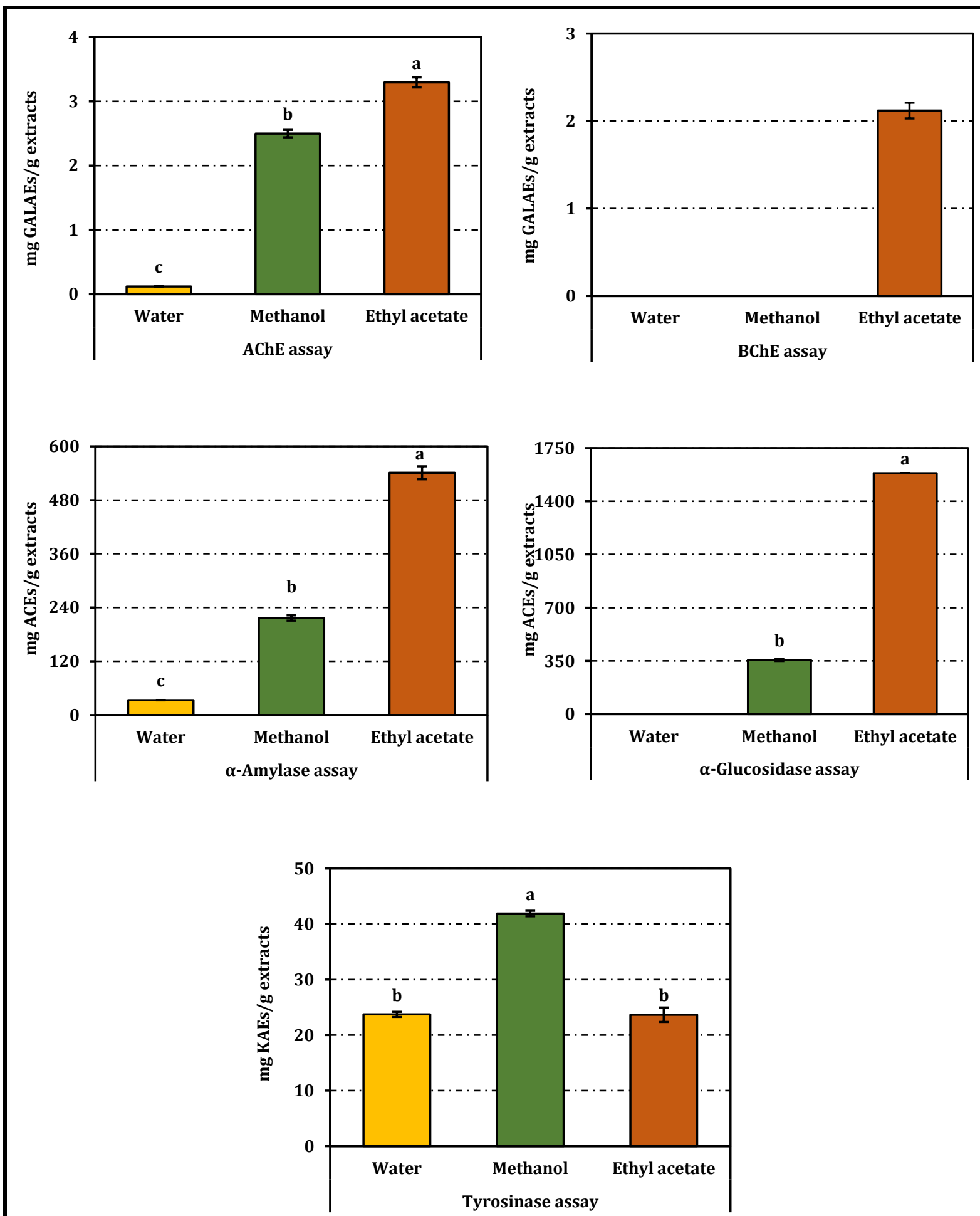
Table 2. Correlations among chemical composition and assays.

\begin{tabular}{llllllllllll}
\hline & 22 & 1 & 2 & 3 & 4 & 5 & 7 & 8 & 9 & 10 & 11 \\
\hline 1 & 0.986 & & & & & & & & & & \\
2 & 0.989 & 0.999 & & & & & & & & & \\
3 & 0.990 & 0.999 & 0.999 & & & & & & & & \\
4 & 0.987 & 0.999 & 0.999 & 0.999 & & & & & & & \\
5 & 0.985 & 0.999 & 0.999 & 0.999 & 0.999 & & & & & & \\
6 & 0.988 & 0.999 & 0.999 & 0.999 & 0.999 & 0.999 & & & & & \\
7 & -0.976 & -0.992 & -0.991 & -0.993 & -0.991 & -0.989 & & & & & \\
8 & -0.993 & -0.999 & -0.999 & -0.999 & -0.999 & -0.999 & 0.987 & & & & \\
9 & 0.991 & 0.997 & 0.998 & 0.997 & 0.998 & 0.998 & -0.981 & -0.999 & & & \\
10 & -0.974 & -0.998 & -0.996 & -0.996 & -0.997 & -0.997 & 0.996 & 0.993 & -0.989 & & \\
11 & -0.989 & -0.999 & -0.999 & -0.999 & -0.999 & -0.999 & 0.993 & 0.999 & -0.997 & 0.997 & \\
12 & 0.989 & 0.999 & 0.999 & 0.999 & 0.999 & 0.999 & -0.991 & -0.999 & 0.998 & -0.996 & -0.999 \\
13 & 0.989 & 0.999 & 0.999 & 0.999 & 0.999 & 0.999 & -0.993 & -0.999 & 0.997 & -0.997 & -0.999 \\
14 & 0.986 & 0.999 & 0.999 & 0.999 & 0.999 & 0.999 & -0.991 & -0.999 & 0.997 & -0.997 & -0.999 \\
15 & 0.987 & 0.999 & 0.999 & 0.999 & 0.999 & 0.999 & -0.993 & -0.999 & 0.997 & -0.997 & -0.999 \\
16 & 0.980 & 0.997 & 0.997 & 0.995 & 0.997 & 0.998 & -0.979 & -0.996 & 0.997 & -0.992 & -0.995 \\
17 & 0.986 & 0.999 & 0.999 & 0.999 & 0.999 & 0.999 & -0.992 & -0.999 & 0.997 & -0.997 & -0.999 \\
18 & 0.989 & 0.999 & 0.999 & 0.999 & 0.999 & 0.998 & -0.996 & -0.998 & 0.995 & -0.997 & -0.999 \\
19 & 0.989 & 0.999 & 0.999 & 0.999 & 0.999 & 0.999 & -0.993 & -0.999 & 0.997 & -0.997 & -0.999 \\
20 & 0.989 & 0.999 & 0.999 & 0.999 & 0.999 & 0.999 & -0.993 & -0.999 & 0.997 & -0.997 & -0.999 \\
21 & 0.989 & 0.999 & 0.999 & 0.999 & 0.999 & 0.999 & -0.993 & -0.999 & 0.997 & -0.997 & -0.999 \\
\hline $1 . D P$
\end{tabular}

1: DPPH, 2: ABTS, 3: CUPRAC, 4: FRAP, 5: FICA, 6: RACI: 7: AChEIA, 8: BChEIA, 9: TIA, 10: AAIA, 11: AGIA, 12: Total flavonoid, 13: Total phenolic, 14: Protocatechuic acid, 15: 4-Hydroxybenzoic acid, 16: Vanillic acid, 17: p-Coumaric acid, 18: Ferulic acid, 19: Hesperidin, 20: Hyperoside, 21: Quercetin, 22: TAP

As detailed in Part 3, the $\mathrm{MeOH}$ extract of $C$. spinosa showed remarkable antioxidant activity. There are many studies on the antioxidant activity of $C$. spinosa in the literature (Nadaroglu et al., 2009; Tlili et al., 2017; Yu et al., 2017; Al-Azawi et al., 2018). In many of these studies, the plant species in question exhibited remarkable antioxidant and radical scavenging activity. Therefore, the data obtained from the present study confirm the literature data. Also, according to the literature data, quercetin (Selway, 1986; Rauha et al., 2000; Guardia et al., 2001; Williams et al., 2004), 4-hydroxybenzoic acid (Duke et al., 2003; Manuja et al., 2013) and p-coumaric acid (Bonina et al., 2002; Ahmad et al., 2006) obtained from this plant may be phytochemicals responsible for the antioxidant activity. However, as mentioned above, the presence of hesperidin and hyperoside in this plant was brought to the literature for the first time with this study. There are some literature data on the contribution of these compounds to antioxidant activity with some other plants or with these compounds themselves (Ku et al., 2014; Hao et al., 2016; Yatao et al., 2018; Gao et al., 2019; He et al., 2019; Kim et al., 2019; Musa et al., 2019; Aggarwal et al., 2020; Huang et al., 2020). These findings support the correlation coefficient data obtained from the present study.

There are some reports in the literature regarding the cholinesterase inhibitory activity of $C$. spinosa. In a study carried out by Mollica et al. (2019), cholinesterase inhibitory activities of extracts obtained from $C$. spinosa by different methods were investigated and it was reported that the highest activity was exhibited by the extract obtained by microwave extraction. In another study by Wojdylo et al. (2019), it was reported that extracts obtained from different developmental stages of $C$. spinosa, especially those rich in flavonols (quercetin, kaempferol, myricetin, and isorhamnetin derivatives), showed significant cholinesterase inhibitory activity. Similar findings were also reported by Mekinic et al. (2018). 
In the current study, the EtOAc extract exhibited the highest cholinesterase inhibitory activity, and according to the data in Table 1, this extract contains high amounts of protocatechuic and 4-hydroxybenzoic acids. There are some reports in the literature that these compounds themselves or some extracts containing high amounts of these compounds exhibit significant cholinesterase inhibitory activity (Szwajgier \& Borowiec, 2012; Ertas et al., 2014; Zengin et al., 2017). These reports corroborate the data from the present study.

According to literature data, $C$. spinosa is considered to be a remarkable anti-hyperglycemic agent, in addition to its biological activities given above. In a study by Mollica et al. (2017), it was reported that $C$. spinosa leaves or buds normalized biochemical parameters and reversed liver/lung damage in streptozocin-induced diabetic rats. The inhibitory activity of $C$. spinosa phytochemicals on $\alpha$-amylase and $\alpha$-glucosidase was also analyzed by in silico methods (Ogunwa et al., 2017). In the aforementioned study, it was reported that naringin and rutin show high affinity for $\alpha$-amylase and $\alpha$-glucosidase. In the present study, EtOAc extract from $C$. spinosa exhibited the highest inhibitory activity on both enzymes. As can be seen from the data in Table 1, protocatechuic and 4-hydroxybenzoic acids are present in high amounts in this extract. Literature data indicate that both compounds may be responsible for the anti-diabetic activity of the extract (Saltan et al., 2017; Alegbe et al., 2019).

There are also some reports in the literature regarding the tyrosinase inhibitory activity of $C$. spinosa. It was determined that quercetin increased tyrosinase expression in B16 murine melanoma cells treated with $C$. spinosa extract at a concentration of $0.03 \%$ (w/v) (Matsuyama et al., 2009). Similar findings have been reported in a different report of the same research group (Matsuyama et al., 2009). In the current study, $\mathrm{MeOH}$ extract exhibited the highest tyrosinase inhibitory activity. According to the data in Table 1, it is thought that the main compounds of the $\mathrm{MeOH}$ extract contribute significantly to this activity. However, the presence of $1335.88 \mu \mathrm{g} / \mathrm{g}$ quercetin in the $\mathrm{MeOH}$ extract creates a contradiction between the data obtained from the current study and the literature data. Therefore, biological activity-guided fractionation is needed to elucidate the compounds that contribute to the activity.

\section{Declaration of Conflicting Interests and Ethics}

The authors declare no conflict of interest. This research study complies with research and publishing ethics. The scientific and legal responsibility for manuscripts published in IJSM belongs to the authors.

\section{Authorship Contribution Statement}

Bulent Kirkan: Investigation and Resources. Olcay Ceylan: Resources. Cengiz Sarikurkcu: Methodology, Visualization, Software, Formal Analysis and Validation. Bektas Tepe: Investigation, Supervision and Writing -original draft.

\section{Orcid}

Bulent Kirkan https://orcid.org/0000-0003-3462-0681
Olcay Ceylan (D) https://orcid.org/0000-0002-4371-2126
Cengiz Sarikurkcu https://orcid.org/0000-0001-5094-2520
Bektas Tepe (D) https://orcid.org/0000-0001-8982-5188

\section{REFERENCES}

Aggarwal, V., Tuli, H.S., Thakral, F., Singhal, P., Aggarwal, D., Srivastava, S., Pandey, A., Sak, K., Varol, M., Khan, M.A., \& Sethi, G. (2020). Molecular mechanisms of action of hesperidin in cancer: Recent trends and advancements. Experimental Biology and Medicine, 245(5), 486-497. 
Ahmad, I., Aqil, F., \& Owais, M. (2006). Modern phytomedicine: Turning medicinal plants into drugs: John Wiley \& Sons.

Al-Azawi, A.H., Ghaima, K.K., \& Salih, H.H. (2018). Phytochemical, antibacterial and antioxidant activities of Capparis spinosa L. Cultivated in iraq. Bioscience Research, 15(3), 2611-2618.

Alegbe, E.O., Terali, K., Olofinsan, K.A., Surgun, S., Ogbaga, C.C., \& Ajiboye, T.O. (2019). Antidiabetic activity-guided isolation of gallic and protocatechuic acids from Hibiscus sabdariffa calyxes. Journal of Food Biochemistry, 43(7).

Aliyazicioglu, R., Eyupoglu, O.E., Sahin, H., Yildiz, O., \& Baltas, N. (2013). Phenolic components, antioxidant activity, and mineral analysis of Capparis spinosa L. African Journal of Biotechnology, 12(47), 6643-6649.

Amarowicz, R., Karamac, M., \& Shahidi, F. (1999). Synergistic activity of capelin protein hydrolysates with synthetic antioxidants in a model system. Journal of Food Lipids, 6(4), 271-275.

Anwar, F., Muhammad, G., Hussain, M.A., Zengin, G., Alkharfy, K.M., Ashraf, M., \& Gilani, A.H. (2016). Capparis spinosa L.: A Plant with High Potential for Development of Functional Foods and Nutraceuticals/ Pharmaceuticals. International Journal of Pharmacology, 12(3), 201-219.

Apak, R., Güçlü, K., Özyürek, M., Esin Karademir, S., \& Erçağ, E. (2006). The cupric ion reducing antioxidant capacity and polyphenolic content of some herbal teas. International Journal of Food Sciences and Nutrition, 57(5-6), 292-304.

Athukorala, Y., Lee, K.W., Song, C., Ahn, C.B., Shin, T.S., Cha, Y.J., Shahidi, F., \& Jeon, Y.J. (2003). Potential antioxidant activity of marine red alga Grateloupia filicina extracts. Journal of Food Lipids, 10(3), 251-265.

Bonina, F., Puglia, C., Ventura, D., Aquino, R., Tortora, S., Sacchi, A., Saija, A., Tomaino, A., Pellegrino, M.L., \& de Capariis, P. (2002). In vitro antioxidant and in vivo photoprotective effects of a lyophilized extract of Capparis spinosa L. buds. Journal of Cosmetic Science, 53(6), 321-336.

Cittan, M., \& Çelik, A. (2018). Development and validation of an analytical methodology based on Liquid Chromatography-Electrospray Tandem Mass Spectrometry for the simultaneous determination of phenolic compounds in olive leaf extract. Journal of Chromatographic Science, 56(4), 336-343.

Cumby, N., Zhong, Y., Naczk, M., \& Shahidi, F. (2008). Antioxidant activity and water-holding capacity of canola protein hydrolysates. Food Chemistry, 109(1), 144-148.

Duke, J.A., Bogenschutz-Godwin, M.J., duCellier, J., \& Duke, P.-A. (2003). CRC Handbook of Medicinal Spices: Boca Raton: CRC Press.

Ertas, A., Boga, M., Yilmaz, M.A., Yesil, Y., Hasimi, N., Kaya, M.S., Temel, H., \& Kolak, U. (2014). Chemical Compositions by Using LC-MS/MS and GC-MS and Biological Activities of Sedum sediforme (Jacq.) Pau. Journal of Agricultural and Food Chemistry, 62(20), 46014609.

Fu, X.P., Aisa, H.A., Abdurahim, M., Yili, A., Aripova, S.F., \& Tashkhodzhaev, B. (2007). Chemical composition of Capparis spinosa fruit. Chemistry of Natural Compounds, 43(2), 181-183.

Fu, X.P., Wu, T., Abdurahim, M., Su, Z., Hou, X.L., Aisa, H.A., \& Wu, H. (2008). New spermidine alkaloids from Capparis spinosa roots. Phytochemistry Letters, 1(1), 59-62.

Gao, Y.T., Fang, L.Y., Wang, X.X., Lan, R.N., Wang, M.Y., Du, G., Guan, W.Q., Liu, J.F., Brennan, M., Guo, H.X., Brennan, C., \& Zhao, H. (2019). Antioxidant Activity Evaluation of Dietary Flavonoid Hyperoside Using Saccharomyces cerevisiae as a Model. Molecules, 24(4), 788. 
Guardia, T., Rotelli, A.E., Juarez, A.O., \& Pelzer, L.E. (2001). Anti-inflammatory properties of plant flavonoids. Effects of rutin, quercetin and hesperidin on adjuvant arthritis in rat. $\mathrm{Il}$ Farmaco, 56(9), 683-687.

Hao, X.L., Kang, Y., Li, J.K., Li, Q.S., Liu, E.L., \& Liu, X.X. (2016). Protective effects of hyperoside against $\mathrm{H} 2 \mathrm{O} 2$-induced apoptosis in human umbilical vein endothelial cells. Molecular Medicine Reports, 14(1), 399-405.

He, J.T., Li, H.Q., Li, G.F., \& Yang, L. (2019). Hyperoside protects against cerebral ischemiareperfusion injury by alleviating oxidative stress, inflammation and apoptosis in rats. Biotechnology \& Biotechnological Equipment, 33(1), 798-806.

Huang, J.Z., Tong, X., Zhang, L., Zhang, Y., Wang, L., Wang, D.G., Zhang, S.J., \& Fan, H. (2020). Hyperoside Attenuates Bleomycin-Induced Pulmonary Fibrosis Development in Mice. Frontiers in Pharmacology, 11, 550955.

Hung, T.M., Na, M., Dat, N.T., Ngoc, T.M., Youn, U., Kim, H.J., Min, B.-S., Lee, J., \& Bae, K. (2008). Cholinesterase inhibitory and anti-amnesic activity of alkaloids from Corydalis turtschaninovii. Journal of Ethnopharmacology, 119(1), 74-80.

Kim, J., Wie, M.B., Ahn, M., Tanaka, A., Matsuda, H., \& Shin, T. (2019). Benefits of hesperidin in central nervous system disorders: a review. Anatomy \& Cell Biology, 52(4), 369-377.

Kocak, M.S., Sarikurkcu, C., Cengiz, M., Kocak, S., Uren, M.C., \& Tepe, B. (2016). Salvia cadmica: Phenolic composition and biological activity. Industrial Crops and Products, 85, 204-212.

Ku, S.K., Kwak, S., Kwon, O.J., \& Bae, J.S. (2014). Hyperoside Inhibits High-Glucose-Induced Vascular Inflammation In Vitro and In Vivo. Inflammation, 37(5), 1389-1400.

Kubo, I., \& Kinst-Hori, I. (1999). Flavonols from saffron flower: tyrosinase inhibitory activity and inhibition mechanism. Journal of Agricultural and Food Chemistry, 47(10), 4121-4125.

Kulisic-Bilusic, T., Schmöller, I., Schnäbele, K., Siracusa, L., \& Ruberto, G. (2012). The anticarcinogenic potential of essential oil and aqueous infusion from caper (Capparis spinosa L.). Food Chemistry, 132(1), 261-267.

Likhitwitayawuid, K. (2008). Stilbenes with tyrosinase inhibitory activity. Current Science, 94(1), 44-52.

Liu, S., Ai, Z., Qu, F., Chen, Y., \& Ni, D. (2017). Effect of steeping temperature on antioxidant and inhibitory activities of green tea extracts against $\alpha$-amylase, $\alpha$-glucosidase and intestinal glucose uptake. Food Chemistry, 234, 168-173.

Liyana-Pathirana, C., Dexter, J., \& Shahidi, F. (2006). Antioxidant properties of wheat as affected by pearling. Journal of Agricultural and Food Chemistry, 54(17), 6177-6184.

Loizzo, M.R., Tundis, R., Conforti, F., Menichini, F., Bonesi, M., Nadjafi, F., Frega, N.G., \& Menichini, F. (2010). Salvia leriifolia Benth (Lamiaceae) extract demonstrates in vitro antioxidant properties and cholinesterase inhibitory activity. Nutrition Research, 30(12), 823-830.

Maisuthisakul, P., \& Gordon, M.H. (2009). Antioxidant and tyrosinase inhibitory activity of mango seed kernel by product. Food Chemistry, 117(2), 332-341.

Manuja, R., Sachdeva, S., Jain, A., \& Chaudhary, J. (2013). A comprehensive review on biological activities of p-hydroxy benzoic acid and its derivatives. International Journal of Pharmaceutical Sciences Review and Research, 22(2), 109-115.

Matsuyama, K., Villareal, M.O., El Omri, A., Han, J., Kchouk, M., \& Isoda, H. (2009). Effect of Tunisian Capparis spinosa L. extract on melanogenesis in B16 murine melanoma cells. Journal of Natural Medicines, 63(4), 468-472.

Mekinic, I.G., Simat, V., Ljubenkov, I., Burcul, F., Grga, M., Mihajlovski, M., Loncar, R., Katalinic, V., \& Skroza, D. (2018). Influence of the vegetation period on sea fennel, 
Crithmum maritimum L. (Apiaceae), phenolic composition, antioxidant and anticholinesterase activities. Industrial Crops and Products, 124, 947-953.

Mollica, A., Stefanucci, A., Macedonio, G., Locatelli, M., Luisi, G., Novellino, E., \& Zengin, G. (2019). Chemical composition and biological activity of Capparis spinosa L. from Lipari Island. South African Journal of Botany, 120, 135-140.

Mollica, A., Zengin, G., Locatelli, M., Stefanucci, A., Mocan, A., Macedonio, G., Carradori, S., Onaolapo, O., Onaolapo, A., Adegoke, J., Olaniyan, M., Aktumsek, A., \& Novellino, E. (2017). Anti-diabetic and anti-hyperlipidemic properties of Capparis spinosa L.: In vivo and in vitro evaluation of its nutraceutical potential. Journal of Functional Foods, 35, 32-42.

Musa, A.E., Omyan, G., Esmaely, F., \& Shabeeb, D. (2019). Radioprotective Effect of Hesperidin: A Systematic Review. Medicina-Lithuania, 55(7).

Nadaroglu, H., Demir, N., \& Demir, Y. (2009). Antioxidant and Radical Scavenging Activities of Capsules of Caper (Capparis spinosa). Asian Journal of Chemistry, 21(7), 5123-5134.

Ng, Z.X., Kuppusamy, U.R., Tajunisah, I., Fong, K.C.S., \& Chua, K.H. (2012). Investigation of SLC2A1 26177A/G gene polymorphism via high resolution melting curve analysis in Malaysian patients with diabetic retinopathy. Journal of Diabetes and its Complications, 26(5), 388-392.

Ng, Z.X., Yong, P.H., \& Lim, S.Y. (2020). Customized drying treatments increased the extraction of phytochemicals and antioxidant activity from economically viable medicinal plants. Industrial Crops and Products, 155, 112815.

Ogunwa, T.H., Adeyelu, T.T., \& Fasimoye, R.Y. (2017). Exploring the molecular mechanism of interaction and inhibitory potential of Capparis spinosa L. phytoconstituents on diabetesrelated targets. Research Journal of Pharmaceutical Biological and Chemical Sciences, $8(5), 237-248$.

Orphanides, A., Goulas, V., \& Gekas, V. (2016). Drying technologies: vehicle to high-quality herbs. Food Engineering Reviews, 8(2), 164-180.

Ozer, M.S., Kirkan, B., Sarikurkcu, C., Cengiz, M., Ceylan, O., Atilgan, N., \& Tepe, B. (2018). Onosma heterophyllum: Phenolic composition, enzyme inhibitory and antioxidant activities. Industrial Crops and Products, 111, 179-184.

Pinho, B.R., Ferreres, F., Valentão, P., \& Andrade, P.B. (2013). Nature as a source of metabolites with cholinesterase-inhibitory activity: an approach to Alzheimer's disease treatment. Journal of Pharmacy and Pharmacology, 65(12), 1681-1700.

Rahimi, V.B., Rajabian, A., Rajabi, H., Vosough, E.M., Mirkarimi, H.R., Hasanpour, M., Iranshahi, M., Rakhshandeh, H., \& Askari, V.R. (2020). The effects of hydro-ethanolic extract of Capparis spinosa (C. spinosa) on lipopolysaccharide (LPS)-induced inflammation and cognitive impairment: Evidence from in vivo and in vitro studies. Journal of Ethnopharmacology, 256, 112706.

Rasouli, H., Hosseini-Ghazvini, S.M.-B., Adibi, H., \& Khodarahmi, R. (2017). Differential $\alpha$ amylase/ $\alpha$-glucosidase inhibitory activities of plant-derived phenolic compounds: a virtual screening perspective for the treatment of obesity and diabetes. Food \& Function, 8(5), 1942-1954.

Rauha, J.-P., Remes, S., Heinonen, M., Hopia, A., Kähkönen, M., Kujala, T., Pihlaja, K., Vuorela, H., \& Vuorela, P. (2000). Antimicrobial effects of Finnish plant extracts containing flavonoids and other phenolic compounds. International Journal Of Food Microbiology, 56(1), 3-12.

Romeo, V., Ziino, M., Giuffrida, D., Condurso, C., \& Verzera, A. (2007). Flavour profile of capers (Capparis spinosa L.) from the Eolian Archipelago by HS-SPME/GC-MS. Food Chemistry, 101(3), 1272-1278. 
Saltan, F.Z., Okutucu, B., Canbay, H.S., \& Ozel, D. (2017). In vitro alpha-Glucosidase and alpha-Amylase Enzyme Inhibitory Effects in Elaeagnus angustifolia Leaves Extracts. Eurasian Journal of Analytical Chemistry, 12(2), 117-126.

Samy, J., Sugumaran, M., Lee, K.L.W., \& Wong, K.M. (2005). Herbs of Malaysia : an introduction to the medicinal, culinary, aromatic and cosmetic use of herbs. Shah Alam, Selangor: Times Editions.

Sarikurkcu, C., Locatelli, M., Mocan, A., Zengin, G., \& Kirkan, B. (2020). Phenolic Profile and Bioactivities of Sideritis perfoliata L.: The Plant, Its Most Active Extract, and Its Broad Biological Properties. Frontiers in Pharmacology, 10, 1642.

Selway, J.W.T. (1986). Antiviral activity of flavones and flavans. Progress in Clinical and Biological Research, 213, 521-536.

Shahidi, F., \& Amarowicz, R. (1996). Antioxidant activity of protein hydrolyzates from aquatic species. Journal of the American Oil Chemists' Society, 73(9), 1197-1199.

Shahidi, F., \& Zhong, Y. (2007). Measurement of Antioxidant Activity in Food and Biological Systems Antioxidant Measurement and Applications (Vol. 956, pp. 36-66): American Chemical Society.

Shahidi, F., \& Zhong, Y. (2015). Measurement of antioxidant activity. Journal of Functional Foods, 18, 757-781.

Snoussi, M., Najett, M., Boumediene, M., \& Abdelallah, M. (2017). In-vitro and In-vivo antifungal activity of Capparis spinosa against eight storage molds, a causal agent of wheat alteration. Research Journal of Pharmaceutical Biological and Chemical Sciences, 8(6), 1318.

Stefanucci, A., Zengin, G., Locatelli, M., Macedonio, G., Wang, C.K., Novellino, E., Mahomoodally, M.F., \& Mollica, A. (2018). Impact of different geographical locations on varying profile of bioactives and associated functionalities of caper (Capparis spinosa L.). Food and Chemical Toxicology, 118, 181-189.

Sun, T., \& Tanumihardjo, S.A. (2007). An integrated approach to evaluate food antioxidant capacity. Journal of Food Science, 72(9), R159-R165.

Szwajgier, D., \& Borowiec, K. (2012). Phenolic acids from malt are efficient acetylcholinesterase and butyrylcholinesterase inhibitors. Journal of the Institute of Brewing, 118(1), 40-48.

Tan, Y., Chang, S.K.C., \& Zhang, Y. (2017). Comparison of $\alpha$-amylase, $\alpha$-glucosidase and lipase inhibitory activity of the phenolic substances in two black legumes of different genera. Food Chemistry, 214, 259-268.

Tepe, B., Sarikurkcu, C., Berk, S., Alim, A., \& Akpulat, H.A. (2011). Chemical composition, radical scavenging and antimicrobial activity of the essential oils of Thymus boveii and Thymus hyemalis. Records of Natural Products, 5(3), 208-220.

Tlili, N., Elfalleh, W., Saadaoui, E., Khaldi, A., Triki, S., \& Nasri, N. (2011). The caper (Capparis L.): Ethnopharmacology, phytochemical and pharmacological properties. Fitoterapia, 82(2), 93-101.

Tlili, N., Feriani, A., Saadoui, E., Nasri, N., \& Khaldi, A. (2017). Capparis spinosa leaves extract: Source of bioantioxidants with nephroprotective and hepatoprotective effects. Biomedicine \& Pharmacotherapy, 87, 171-179.

Trombetta, D., Occhiuto, F., Perri, D., Puglia, C., Santagati, N.A., Pasquale, A.D., Saija, A., \& Bonina, F. (2005). Antiallergic and antihistaminic effect of two extracts of Capparis spinosa L. flowering buds. Phytotherapy Research, 19(1), 29-33.

Williams, R.J., Spencer, J.P.E., \& Rice-Evans, C. (2004). Flavonoids: antioxidants or signalling molecules? Free Radical Biology and Medicine, 36(7), 838-849. 
Wojdylo, A., Nowicka, P., Grimalt, M., Legua, P., Almansa, M.S., Amoros, A., CarbonellBarrachina, A.A., \& Hernandez, F. (2019). Polyphenol Compounds and Biological Activity of Caper (Capparis spinosa L.) Flowers Buds. Plants-Basel, 8(12).

Yanishlieva, N.V., \& Marinova, E.M. (2001). Stabilisation of edible oils with natural antioxidants. European Journal of Lipid Science and Technology, 103(11), 752-767.

Yatao, X., Saeed, M., Kamboh, A.A., Arain, M.A., Ahmad, F., Suheryani, I., Abd El-Hack, M.E., Alagawany, M., Shah, Q.A., \& Chao, S. (2018). The potentially beneficial effects of supplementation with hesperidin in poultry diets. Worlds Poultry Science Journal, 74(2), 265-276.

Yu, L., Yang, J.H., Wang, X., Jiang, B., Sun, Y.X., \& Ji, Y.B. (2017). Antioxidant and antitumor activities of Capparis spinosa L. and the related mechanisms. Oncology Reports, 37(1), 357-367.

Zengin, G., Uren, M.C., Kocak, M.S., Gungor, H., Locatelli, M., Aktumsek, A., \& Sarikurkcu, C. (2017). Antioxidant and Enzyme Inhibitory Activities of Extracts from Wild Mushroom Species from Turkey. International Journal of Medicinal Mushrooms, 19(4), 327-336.

Zhang, H., Lei, Z., Tian, R., \& Wang, Z. (2018). Polyamidoamine starburst dendrimer-activated chromatography paper-based assay for sensitive detection of telomerase activity. Talanta, $178,116-121$. 